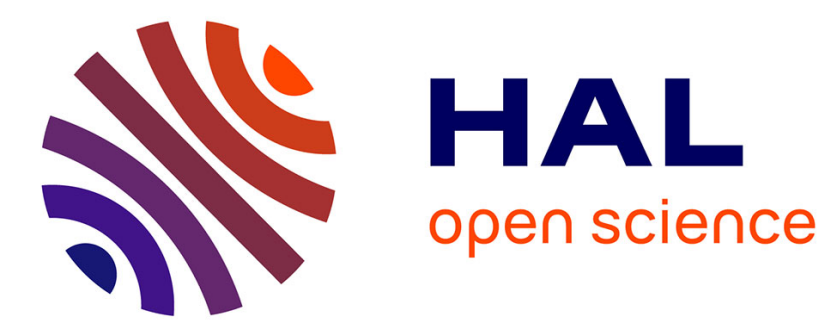

\title{
Do forests represent a long-term source of contaminated particulate matter in the Fukushima Prefecture?
}

J. Patrick Laceby, Sylvain Huon, Yuichi Onda, Veronique Vaury, O. Evrard

\section{To cite this version:}

J. Patrick Laceby, Sylvain Huon, Yuichi Onda, Veronique Vaury, O. Evrard. Do forests represent a long-term source of contaminated particulate matter in the Fukushima Prefecture?. Journal of Environmental Management, 2016, 183, pp.742 - 753. 10.1016/j.jenvman.2016.09.020 . hal-01587510

\author{
HAL Id: hal-01587510 \\ https://hal.science/hal-01587510
}

Submitted on 20 Oct 2017

HAL is a multi-disciplinary open access archive for the deposit and dissemination of scientific research documents, whether they are published or not. The documents may come from teaching and research institutions in France or abroad, or from public or private research centers.
L'archive ouverte pluridisciplinaire HAL, est destinée au dépôt et à la diffusion de documents scientifiques de niveau recherche, publiés ou non, émanant des établissements d'enseignement et de recherche français ou étrangers, des laboratoires publics ou privés. 
Research article

\title{
Do forests represent a long-term source of contaminated particulate matter in the Fukushima Prefecture?
}

\author{
J. Patrick Laceby ${ }^{\mathrm{a},}{ }^{*}$, Sylvain Huon ${ }^{\mathrm{b}}$, Yuichi Onda ${ }^{\mathrm{c}}$, Veronique Vaury ${ }^{\mathrm{b}}$, Olivier Evrard ${ }^{\mathrm{a}}$ \\ a Laboratoire des Sciences du Climat et de l'Environnement (LSCE/IPSL), Unité Mixte de Recherche 8212 (CEA/CNRS/UVSQ), Université Paris-Saclay, Centre de \\ Recherche du CNRS - Bât, 12 - Avenue de la terrasse, 91198 Gif-sur-Yvette, France \\ b Sorbonne Universités, UPMC Univ Paris 06, Institut d'Ecologie et des Sciences de l'Environnement de Paris (iEES), Case 120, 4 Place Jussieu, 75252 Paris \\ Cedex 05, France \\ ${ }^{\mathrm{c}}$ Center for Research in Isotopes and Environmental Dynamics, University of Tsukuba, Tennodai, Tsukuba, Ibaraki 305-8572, Japan
}

Keywords:

FDNPP

Sediment fingerprinting

Sediment tracing

Organic matter

Stable isotopes

Japan

\begin{abstract}
A B S T R A C T
The Fukushima Daiichi Nuclear Power Plant (FDNPP) accident resulted in radiocesium fallout contaminating coastal catchments of the Fukushima Prefecture. As the decontamination effort progresses, the potential downstream migration of radiocesium contaminated particulate matter from forests, which cover over $65 \%$ of the most contaminated region, requires investigation. Carbon and nitrogen elemental concentrations and stable isotope ratios are thus used to model the relative contributions of forest, cultivated and subsoil sources to deposited particulate matter in three contaminated coastal catchments. Samples were taken from the main identified sources: cultivated $(n=28)$, forest $(n=46)$, and subsoils $(n=25)$. Deposited particulate matter $(n=82)$ was sampled during four fieldwork campaigns from November 2012 to November 2014. A distribution modelling approach quantified relative source contributions with multiple combinations of element parameters (carbon only, nitrogen only, and four parameters) for two particle size fractions $(<63 \mu \mathrm{m}$ and $<2 \mathrm{~mm}$ ). Although there was significant particle size enrichment for the particulate matter parameters, these differences only resulted in a $6 \%$ (SD 3\%) mean difference in relative source contributions. Further, the three different modelling approaches only resulted in a $4 \%$ (SD 3\%) difference between relative source contributions. For each particulate matter sample, six models (i.e. $<63 \mu \mathrm{m}$ and $<2 \mathrm{~mm}$ from the three modelling approaches) were used to incorporate a broader definition of potential uncertainty into model results. Forest sources were modelled to contribute $17 \%$ (SD 10\%) of particulate matter indicating they present a long term potential source of radiocesium contaminated material in fallout impacted catchments. Subsoils contributed $45 \%$ (SD 26\%) of particulate matter and cultivated sources contributed 38\% (SD 19\%). The reservoir of radiocesium in forested landscapes in the Fukushima region represents a potential long-term source of particulate contaminated matter that will require diligent management for the foreseeable future.
\end{abstract}

\section{Introduction}

The Fukushima Daiichi Nuclear Power Plant (FDNPP) accident deposited a significant quantity of radionuclides over Japanese soils (Chino et al., 2011; Evrard et al., 2015; Groëll et al., 2014). Of these radionuclides, radiocesium represents the most serious threat for the foreseeable future (Kitamura et al., 2014; Saito and Onda, 2015). Radiocesium is quickly and almost irreversibly bound to fine soil particles (Saito et al., 2014; Sawhiney, 1972) and predominantly

\footnotetext{
* Corresponding author.

E-mail address: placeby@lsce.ipsl.fr (J.P. Laceby).
}

stored within the top five centimetres of undisturbed soil profiles (Lepage et al., 2015; Matsuda et al., 2015). As the majority ( 66\%) of the landscape receiving high levels of radiocesium fallout (i.e. $>1000 \mathrm{kBq} \mathrm{m}^{-2}$ ) were a mixture of evergreen and deciduous forests (Hashimoto et al., 2012), a significant quantity of radiocesium is also stored within the forest canopy, leaf litter, and soil organic matter (Hashimoto et al., 2013; Koarashi et al., 2012; Loffredo et al., 2014).

Japanese authorities have conducted an extensive decontamination program targeting mainly rural residential and cultivated landscapes, including paddy fields (Sakai et al., 2014; Yasutaka and Naito, 2016). Among other activities, decontamination removes 
vegetation and replaces topsoil $(\sim 5 \mathrm{~cm})$. As these rural residential areas are progressively decontaminated, forests will become the main reservoir of radiocesium contamination. Importantly, these radiocesium contaminated forests are typically upslope, or upstream, of decontaminated landscapes.

In this region, researchers have demonstrated that rice paddy fields are a major sediment source (Chartin et al., 2013; Lepage et al., 2016). Conversely, soil erosion and radiocesium export from forest environments is thought to be limited (Shinomiya et al., 2014; Yoshimura et al., 2015) as a thick litter layer of organic matter covers the soil surface, minimizing rainfall driven soil erosion. A key question for ongoing radiocesium management is whether contaminated forest landscapes represent a potential source of radiocesium to downstream and downslope environments.

One approach to examining the potential of forested landscapes to contribute contaminated particulate matter downstream is to directly trace the properties of this material back to their potential sources. Sediment tracing techniques provide a direct method of determining sediment provenance (for reviews, please see: Collins and Walling, 2004; Davis and Fox, 2009; Guzmán et al., 2013; Haddadchi et al., 2013; Koiter et al., 2013). Sediment tracing research has demonstrated that large dams reduce downstream migration of contaminated sediments (Lepage et al., 2016), that decontamination reduces downstream radiocesium transfers (Evrard et al., in review), and that alluvial soils, and the rice paddies occupying them, contribute disproportionately more sediment downstream relative to their spatial extent in the Fukushima region (Lepage et al., 2016).

In this study, the composition of particle borne organic matter is used to test the hypothesis that forested landscapes are a potential source of contaminated matter in three coastal catchments of the Fukushima Prefecture. In particular, source contributions (i.e. cultivated, subsoil, forest) are quantified with the analyses and modelling of total organic carbon (TOC), total nitrogen (TN) and carbon and nitrogen stable isotope ratios $\left(\delta^{13} \mathrm{C}\right.$ and $\left.\delta^{15} \mathrm{~N}\right)$. These parameters have been effectively used to trace the source of sediment and particulate matter (Fox and Papanicolaou, 2007; Laceby et al., 2015b; McConnachie and Petticrew, 2006). Soil $\delta^{15} \mathrm{~N}$ increases with depth in the soil profile (Amundson et al., 2003; Natelhoffer and Fry, 1988) whereas TOC and TN decrease (Blake et al., 2006; Owens et al., 2006). Tillage and harvesting also reduce TOC and TN concentrations, potentially allowing for cultivated sources to have intermediate concentrations relative to surface and subsoils (Juracek and Ziegler, 2009; Walling and Woodward, 1995). $\delta^{13} \mathrm{C}$ discriminates between particulate material derived from landscapes with $C_{3}$ vegetation (e.g. the majority of tree or temperate grass species) compared to $C_{4}$ vegetation (e.g. several grass and cropping species predominantly found in warmer climates) (Fry, 2006; Mariotti and Peterschmitt, 1994; Schimel, 1993). The combination of these organic matter parameters will be used in three contaminated coastal catchments of the Fukushima Prefecture to investigate the potential of forest sources to supply contaminated matter downstream to recently decontaminated landscapes or landscapes less contaminated by the FDNPP accident.

\section{Material and methods}

\subsection{Study site}

Sampling occurred in the Mano $\left(171 \mathrm{~km}^{2}\right)$, Niida $\left(265 \mathrm{~km}^{2}\right)$ and Ota $\left(77 \mathrm{~km}^{2}\right)$ catchments (Fig. 1). The main relief features of these catchments include an upstream coastal mountain range and a more densely populated coastal plain. The upstream catchment areas have total radiocesium $\left({ }^{134} \mathrm{Cs}+{ }^{137} \mathrm{Cs}\right)$ inventories ranging from approximately $20 \mathrm{kBq} \mathrm{kg}^{-1}$ to $150 \mathrm{kBq} \mathrm{kg}^{-1}$ compared to inventories of $<20 \mathrm{kBq} \mathrm{kg}^{-1}$ on the coastal plain (Fig. 1) (Chartin et al., 2013). The mean land use for these catchments, classified with data the Biodiversity Center of Japan (BCJ (2016)) and satellite imagery from Google Earth (version 7.1.5.1557) is 75\% forest (SD 3\%), 16\% cultivated (SD 1\%), $5 \%$ rural farmland (SD 1\%) and 2\% urban (SD 1\%) (Fig. 2). Coniferous forests comprise the majority of forests, and paddy fields are the main cultivated land use. Mean annual rainfall, for the region within $100 \mathrm{~km}$ from the FDNPP, is $1420 \mathrm{~mm} \mathrm{y}^{-1}$ (Laceby et al., 2016) and the rainfall regime drives the downstream migration of radiocesium (Chartin et al., in review; Evrard et al., 2014).

\subsection{Field sampling}

In-stream samples of particle borne organic matter were obtained during four fieldwork campaigns between November 2012 and November 2014. Sampling occurred after each typhoon season in early November and after the spring snow melt, in May 2013. These time periods represent the major hydro-sedimentary events in this region. Deposited fine particulate material $(n=82)$ was sampled during each campaign at multiple sites (Fig. 1) with surface scrapes using a plastic spatula (e.g. the top $1 \mathrm{~cm}$ of deposited material). Each sample was comprised of $\sim 10$ subsamples ( $\sim 5 \mathrm{~g}$ per subsample) of deposited particle borne organic matter collected along a $5 \mathrm{~m}$ river reach. For the remainder of the text, particle borne organic matter will be referred to as particulate matter. This material includes sediment and mineral-bound organic matter trapped in soil micro-aggregates released by soil erosion (Lützow et al., 2006; Mikutta et al., 2006; Remusat et al., 2012), adsorbed or occluded in clay minerals (Vogel et al., 2014) and non-mineral bound organic matter (e.g. litterfalls, roots and other vegetation debris) (Feller and Beare, 1997; Gregorich et al., 2006).

Soil samples were collected from the dominant sources identified through a literature review (Evrard et al., 2015), multiple field campaigns, and stakeholder consultation. Sources included 46 forest soil samples (15 deciduous, 16 coniferous, and 15 mixed), 28 cultivated soil samples (14 rice paddy fields and 14 other fields), and 25 subsoil samples ( 15 decontaminated soil and 10 channel bank and subsoil erosion scars) (Fig. 2). A small plastic trowel was used to sample surface sources, compositing 10 sidewall scrape subsamples (top 1-2 cm, $\sim 5 \mathrm{~g}$ ) into one sample with decontaminated soils being sampled similarly to surface soils. Subsoil erosion scars were sampled by first scraping away the exposed surface sidewall of channel banks and hillslope erosion scars and then subsampling the manually exposed subsoil with 10 plastic trowel grabs that were composited into one sample.

\subsection{Sample processing and analyses}

Samples were dried in a ventilated oven at low temperature $\left(40^{\circ} \mathrm{C}\right)$ to avoid possible desorption of organic matter bound to clay minerals with swelling layers (Bailey, 1980; Remusat et al., 2012), thoroughly homogenized and dry-sieved to $<2 \mathrm{~mm}$ to remove stones and coarse vegetation debris. A subsample of this material was wet-sieved to $<63 \mu \mathrm{m}$ with deionized water (Zirbser et al., 2001). The recovered $<63 \mu \mathrm{m}$ size fraction was oven-dried at $40{ }^{\circ} \mathrm{C}$. In post FDNPP accident research, reports indicated that radiocesium activities were evident in both fine and coarse particle size fractions. For example, Tanaka et al. (2014) found that the silt and sand fractions contained $95 \%$ of the total ${ }^{137} \mathrm{Cs}$ activities in suspended sediment. Furthermore, radiocesium is contained within the tree canopy, leaf litter and soil organic matter in contaminated forests (Evrard et al., 2015; Kato et al., 2012; Loffredo 


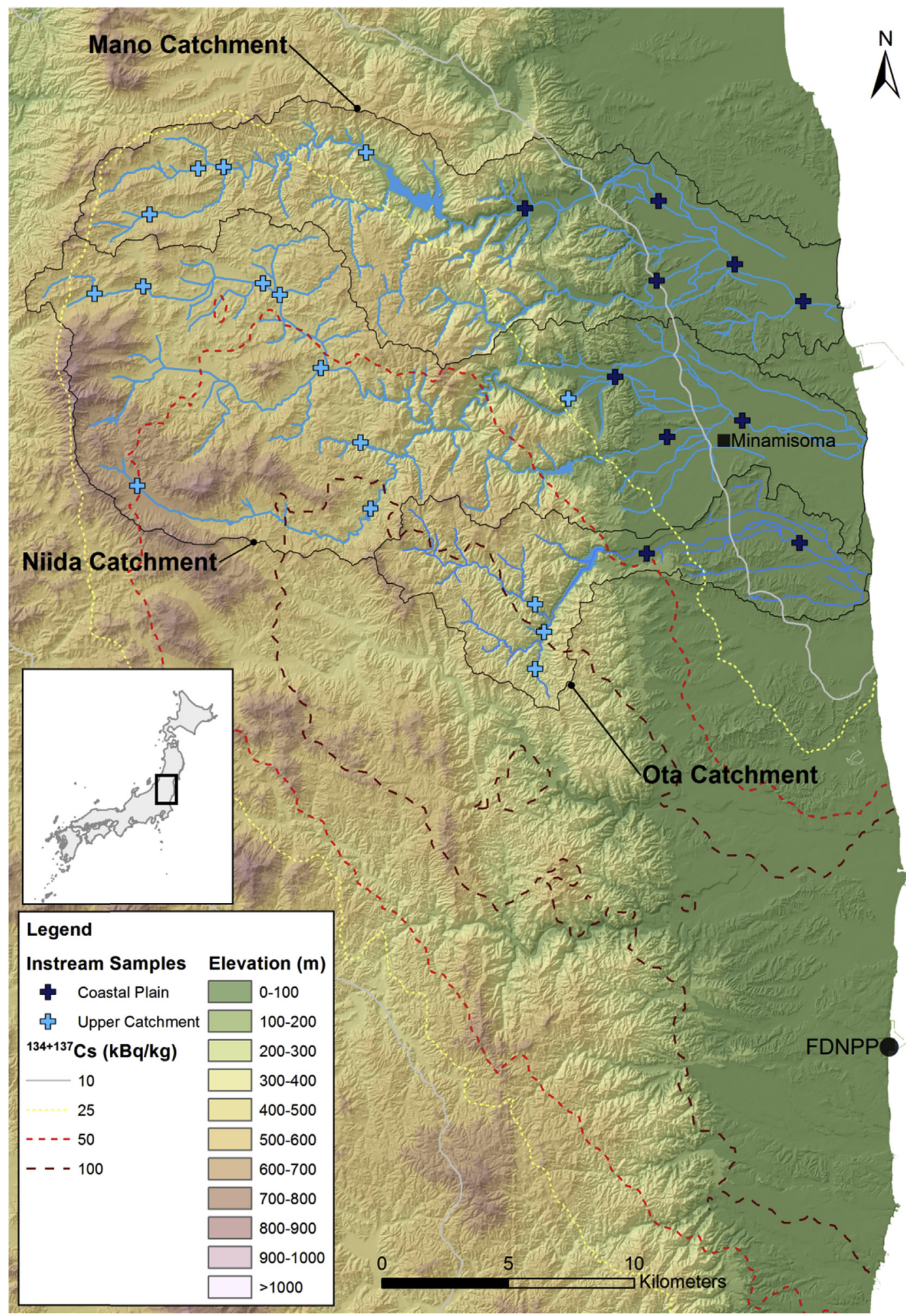

Fig. 1. Catchment location and FDNPP contamination plume with elevation and the location of instream particulate matter samples.

et al., 2014). Accordingly, this current study compares contaminated source contributions to both the $<2 \mathrm{~mm}$ (bulk) and $<63 \mu \mathrm{m}$ (fine) fractions. The normalized enrichment for each parameter (i.e. TOC, TN, $\delta^{13} \mathrm{C}$, and $\delta^{15} \mathrm{~N}$ ) was quantified by dividing the particulate matter parameter in $<63 \mu \mathrm{m}$ fraction by the $<2 \mathrm{~mm}$ fraction. Significant particle size enrichment in the particulate matter parameters and differences in modelled source contributions between these fractions were evaluated with two-tailed paired t-tests or Wilcoxon signed-rank tests with the latter used for comparisons with non-normal distributions or unequal variance (Dytham, 2003; Sokal and Rohlf, 1981).

The fractionated samples were finely ground using an agate 


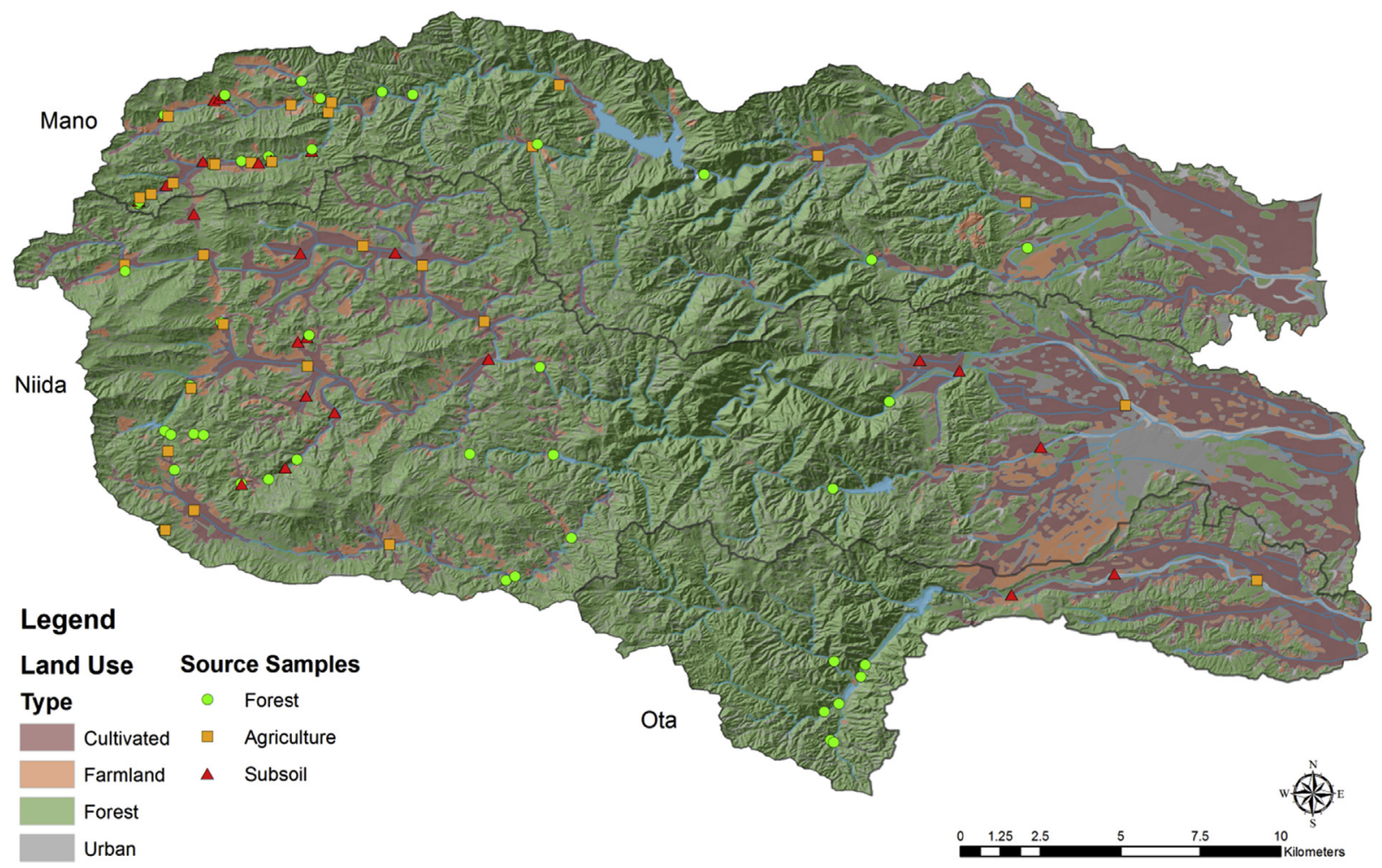

Fig. 2. Catchment land use and source sampling locations.

mortar, weighed and packed into tin capsules for analysis. A random selection of $40 \%$ of the particulate matter samples were treated with a $10 \% \mathrm{HCl}$ solution to test for the potential presence of carbonate minerals. No $\mathrm{CO}_{2}$ bubbling, typical for the dissolution of carbonates, was observed indicating that carbon was organic in nature (Gourdin et al., 2015). The EA-IRMS analyses were conducted with a continuous flow Elementar ${ }^{\circledR}$ VarioPyro cube analyzer coupled to a Micromass ${ }^{\circledR}$ Isoprime Isotope Ratio Mass Spectrometer (IRMS) at the Institute of Ecology and Environmental Science (iEES) in Paris. All samples were first analyzed for TOC and $\delta^{13} \mathrm{C}$ using a set of tyrosine standards to calibrate TOC and TN concentrations, and $\delta^{13} \mathrm{C}$ measurements. Due to low TN contents, a second run was performed on separate sample aliquots in order to optimize sample weight for $\delta^{15} \mathrm{~N}$ measurements. Oxygen for combustion was injected during $70 \mathrm{~s}\left(30 \mathrm{~mL} \mathrm{~min}^{-1}\right)$ and temperatures were set at $850{ }^{\circ} \mathrm{C}$ and $1120{ }^{\circ} \mathrm{C}$ for the reduction and combustion furnaces, respectively (Agnihotri et al., 2014). Analytical precision was quantified with replicate analyses of a tyrosine standard $(n=297)$ calibrated against international reference standards (Coplen et al., 1983; Girardin and Mariotti, 1991). Mean analytical uncertainties were $0.3 \%$ for TN, $0.1 \%$ for TOC, $0.1 \%$ for $\delta^{13} \mathrm{C}$ (vs. PBD) and $0.2 \%$ for $\delta^{15} \mathrm{~N}$ (vs. Air). All source soil and particulate matter data are provided in Supplementary Information Tables S6 and S7 respectively.

\subsection{Statistical analyses and source modelling}

Two-tailed t-tests examined statistical differences between source groupings with normal distributions (tested with the Shapiro-Wilke test) and equal variance (tested with the f-test). Mann-Whitney $U$-tests examined statistical differences between groups with non-normal distributions or unequal variance (Dytham, 2003; Sokal and Rohlf, 1981). These analyses were performed on both particle size fractions. Three combinations of particulate matter parameters were modelled: 1) TN and $\delta^{15} \mathrm{~N}$ (the $\mathrm{N}$ model); 2) TOC and $\delta^{13} \mathrm{C}$ (the $\mathrm{C}$ model); 3) all 4 properties (the $\mathrm{C}+\mathrm{N}$ model). These combinations were used to quantify relative source contributions with a concentration weighted distribution modelling approach (Laceby et al., 2015b; Le Gall et al., 2016):

$$
\begin{aligned}
M M D= & \left.\left.\left.A B S \quad C_{i}-\sum_{s=1}^{m} S_{s i} x_{s}\right)\right) / C_{i}\right) \\
& \left.\left.+ \text { ABS } \quad C_{r}-\left(\left(\sum_{s=1}^{m} S_{s r} W_{s} x_{s}\right) /\left(\sum_{s=1}^{m} W_{s} x_{s}\right)\right)\right) / C_{r}\right)
\end{aligned}
$$

where $C_{i}$ is the TOC or TN concentration in the particulate matter, $S_{S i}$ is the TOC or TN $(i)$ concentration in the soil source $(s), C_{r}$ is the carbon or nitrogen isotopic ratio $(r)$ in the particulate matter, $\mathrm{S}_{\mathrm{sr}}$ is the isotopic ratio $(r)$ in the source $(s), W_{s i}$ is the TOC or TN concentration in source (s) which is used to weight the respective carbon or nitrogen isotopic ratio $(r), \mathrm{x}_{\mathrm{S}}$ is modelled as the relative contribution of source (s); and MMD is the mixing model difference which is minimized when summing absolute values (ABS) and solving Eq. (1). Non-negative constraints were imposed on the elemental concentrations and Pearson product-moment correlation coefficients were used to incorporate within source correlations between elemental parameters directly into the modelling process (Laceby and Olley, 2015).

The Shaprio-Wilke test was used to determine whether source element properties should be modelled as normal distributions. Source properties that were non-normal were fit with alternative distributions with Oracle's Crystal Ball Software that uses maximum likelihood estimation calculations to select the best fit of 14 potential distributions with Anderson-Darling, KolmogorovSmirnoff and Chi-Square tests. For instream particulate matter samples, normal distributions were fit around each parameter, 
using analytical uncertainty to act as the particulate matter parameter standard deviation similarly to Wilkinson et al. (2015) and Evrard et al. (2016).

Eq. (1) was solved with the Optquest algorithm in Oracle's Crystal Ball Software (for examples, see: Foucher et al., 2015; Haddadchi et al., 2014; Laceby and Olley, 2015). To model one relative source contribution, the mixture mean and mixture standard deviation for each source's contribution distribution $\left(x_{S}\right.$ in Eq. (1)) were randomly simulated when solving Eq. (1) 2500 times by minimizing the median MMD with 2500 random samples (Latin Hypercube - 500 bins) simulated for each source and particulate matter distribution. This model solving process was then repeated 2500 times with the median relative source contribution $\left(x_{s}\right)$ from these 2500 additional simulations reported as each source's contribution.

Model uncertainty was calculated by summing the standard deviation of each source's relative contribution, the modelled median absolute deviation (MAD) of these contributions, and the MAD of the modelled standard deviation for the 2500 model simulations (Laceby et al., 2015a). Paired two-tailed t-tests or Wilcoxon signedrank tests compare source contribution results derived from modelling different organic properties (i.e. $\mathrm{C}, \mathrm{N}$ or $\mathrm{C}+\mathrm{N}$ models) depending on normality and variance. Sigmaplot (v. 12.5) was used for all statistical analyses and plotting with the exception of the Pearson product-moment correlation coefficients which were calculated with the Microsoft Excel analysis took-pack add-in.

\section{Results}

\subsection{Source discrimination}

The source sampling design examined potential discrimination among seven sub-sources from three main source categories: subsoils, including decontaminated soils and subsoil erosion scars; cultivated, including rice paddies and other cultivated soils; and forests, including soils underlying deciduous, coniferous and mixed forests. None of the particulate matter parameters significantly discriminated between decontaminated soils and subsoil erosion scars for both particle size fractions (Table 1) indicating that these samples should be combined into one subsoil source for modelling. For the forest sub-sources, only $\delta^{13} \mathrm{C}$ significantly discriminated between coniferous and mixed forest sources for the $<2 \mathrm{~mm}$ fraction, indicating that these sources should be also combined into one source. Paddy and other cultivated sources were significantly different for all particulate matter parameters, except $\delta^{13} \mathrm{C}$, for the $2 \mathrm{~mm}$ fraction. For $<63 \mu \mathrm{m}$ fraction, only $\delta^{15} \mathrm{~N}$ discriminated between paddy and other cultivated sources. As both particle size fractions ( $<63 \mu \mathrm{m}$ and $<2 \mathrm{~mm}$ ) are being modelled, these cultivated sources are combined into one source. Although these two sub- sources are combined, there may be potential for $\delta^{15} \mathrm{~N}$ to discriminate between paddy fields and other cultivated sources in this and other similar regions. For the three main particulate matter sources, all tracer parameters significantly discriminated between forests and cultivated sources, and between forests and subsoil sources (Table 2). TOC and TN significantly discriminated between subsoils and cultivated sources.

\subsection{Particle size}

The majority of particulate matter parameters were significantly enriched in the $<63 \mu \mathrm{m}$ fraction relative to the $<2 \mathrm{~mm}$ fraction. TOC was significantly enriched in subsoils and cultivated sources and particulate matter sampled in the Mano catchment (Fig. 3A, Table S1). TN was significantly enriched in subsoils and cultivated sources along with particulate matter from the Mano and Niida catchments (Fig. 3B). $\delta^{15} \mathrm{~N}$ was significantly enriched in subsoil and forest sources, along with particulate matter from the Ota catchment (Fig. 3D). Although there was significant ${ }^{13} \mathrm{C}$ enrichment for all sources and particulate matter samples (Fig. $3 \mathrm{C}$ ), the average source $\delta^{13} \mathrm{C}$ increase was only $3 \%$ (SD $0.2 \%$ ), compared to $32 \%$ for TN (SD 25\%), $23 \%$ for TOC (SD 19\%) and $20 \%$ for $\delta^{15} \mathrm{~N}$ (SD 12\%). The average catchment particulate matter parameters were $4 \%$ (SD $4 \%$ ) more enriched than the source samples reflecting the potential impact of fluvial sorting processes on these parameters. Furthermore, for the particulate matter samples only $19 \%$ (SD 13\%) of the material sampled was fractionated to $<63 \mu \mathrm{m}$ compared to $23 \%$ (SD $12 \%$ ) for the source samples likely resulting in the observed $4 \%$ enrichment in the particulate matter parameters. The fact that more than $80 \%$ of the particulate material sampled was $>63 \mu \mathrm{m}$ is indicative of the coarse material being transported and deposited after significant erosive events in these catchments.

There were 12 forest source samples with insufficient material in the $<63 \mu \mathrm{m}$ fraction for analysis. These samples were taken from a mixture of deciduous $(n=2)$, coniferous $(n=5)$, and mixed forests $(n=2)$ and were comprised predominantly of leaf litter and coarse soil organic matter. This indicates that these samples should have been taken from a greater depth in order to penetrate the thick layer of organic matter found in forests in this region. As these samples reflect a potential source of particulate matter they were included in the modelled forest source samples for the $<2 \mathrm{~mm}$ fraction, but excluded from the $<63 \mu \mathrm{m}$ fraction owing to the lack of data. These 12 forest source samples were also excluded from the particle size analysis above.

Three instream particulate matter samples were comprised of only coarse sandy material and not analyzed. One particulate matter sample had only $<63 \mu \mathrm{m}$ and no $<2 \mathrm{~mm}$ material and seven samples had only $<2 \mathrm{~mm}$ and no $<63 \mu \mathrm{m}$ material. These latter samples, which were excluded from further analyses, are again

Table 1

Two-tailed $t$-test and Mann Whitney $U$ test results (p-values) examining significant differences between potential sub-sources.

\begin{tabular}{|c|c|c|c|c|c|}
\hline Source comparison: 7 sources & Particle size & TOC & $\mathrm{TN}$ & $\delta^{13} \mathrm{C}$ & $\delta^{15} \mathrm{~N}$ \\
\hline Decontaminated vs & $2 \mathrm{~mm}$ & 0.912 & 0.284 & $0.072^{\mathrm{b}}$ & $0.648^{\mathrm{b}}$ \\
\hline Subsoil Sources & $63 \mu \mathrm{m}$ & 0.934 & 0.737 & 0.192 & $0.609^{\mathrm{b}}$ \\
\hline Cultivated vs Paddy & $2 \mathrm{~mm}$ & $0.023^{\mathrm{a}}$ & $0.048^{\mathrm{a}}$ & $0.361^{\mathrm{b}}$ & $0.003^{\mathrm{ab}}$ \\
\hline Sources & $63 \mu \mathrm{m}$ & $0.141^{\mathrm{b}}$ & $0.092^{\mathrm{b}}$ & 0.260 & $0.014^{\mathrm{ab}}$ \\
\hline Coniferous vs & $2 \mathrm{~mm}$ & $0.838^{\mathrm{b}}$ & $0.660^{\mathrm{b}}$ & $0.221^{\mathrm{b}}$ & $0.753^{\mathrm{b}}$ \\
\hline Deciduous Forests & $63 \mu \mathrm{m}$ & $0.709^{\mathrm{b}}$ & $0.911^{\mathrm{b}}$ & 0.087 & $0.747^{\mathrm{b}}$ \\
\hline Coniferous vs Mixed & $2 \mathrm{~mm}$ & $0.898^{\mathrm{b}}$ & $0.751^{\mathrm{b}}$ & $0.015^{\mathrm{ab}}$ & $0.343^{\mathrm{b}}$ \\
\hline Forests & $63 \mu \mathrm{m}$ & $0.783^{\mathrm{b}}$ & $0.421^{\mathrm{b}}$ & $0.057^{\mathrm{b}}$ & $0.247^{\mathrm{b}}$ \\
\hline Deciduous vs Mixed & $2 \mathrm{~mm}$ & $0.950^{\mathrm{b}}$ & $0.957^{\mathrm{b}}$ & $0.339^{\mathrm{b}}$ & $0.376^{\mathrm{b}}$ \\
\hline Forests & $63 \mu \mathrm{m}$ & $0.570^{\mathrm{b}}$ & $0.495^{\mathrm{b}}$ & $0.760^{\mathrm{b}}$ & $0.359^{\mathrm{b}}$ \\
\hline
\end{tabular}

a Indicates samples were significantly different (i.e. p-value <0.05).

b Indicating samples that were normally distributed with equal variances (i.e. t-tests). 
Table 2

Two-tailed $t$-test and Mann Whitney $U$ test results (p-values) examining significant differences between the main sources.

\begin{tabular}{|c|c|c|c|c|c|}
\hline Source comparison: 3 sources & Particle size & TOC & $\mathrm{TN}$ & $\delta^{13} \mathrm{C}$ & $\delta^{15} \mathrm{~N}$ \\
\hline Subsoil vs Cultivated & $2 \mathrm{~mm}$ & $<0.001^{\mathrm{a}}$ & $<0.001^{\mathrm{a}}$ & $0.682^{\mathrm{b}}$ & 0.412 \\
\hline Sources & $63 \mu \mathrm{m}$ & $<0.001^{\mathrm{a}}$ & $<0.001^{\mathrm{a}}$ & 0.728 & $0.574^{\mathrm{b}}$ \\
\hline Subsoil vs Forest & $2 \mathrm{~mm}$ & $<0.001^{\mathrm{a}}$ & $<0.001^{\mathrm{a}}$ & $<0.001^{\mathrm{ab}}$ & $0.004^{\mathrm{a}}$ \\
\hline Sources & $63 \mu \mathrm{m}$ & $<0.001^{\mathrm{a}}$ & $<0.001^{\mathrm{a}}$ & $<0.001$ & $<0.001^{\mathrm{a}}$ \\
\hline Cultivated vs Forest & $2 \mathrm{~mm}$ & $<0.001^{\mathrm{a}}$ & $<0.001^{\mathrm{a}}$ & $<0.001^{\mathrm{ab}}$ & $<0.001^{\mathrm{a}}$ \\
\hline Sources & $63 \mu \mathrm{m}$ & $<0.001^{\mathrm{a}}$ & $<0.001^{\mathrm{a}}$ & $<0.001$ & $<0.001^{\mathrm{a}}$ \\
\hline
\end{tabular}

a Indicates samples were significantly different (i.e. p-value <0.05).

b Indicating samples that were normally distributed with equal variances (i.e. t-tests).
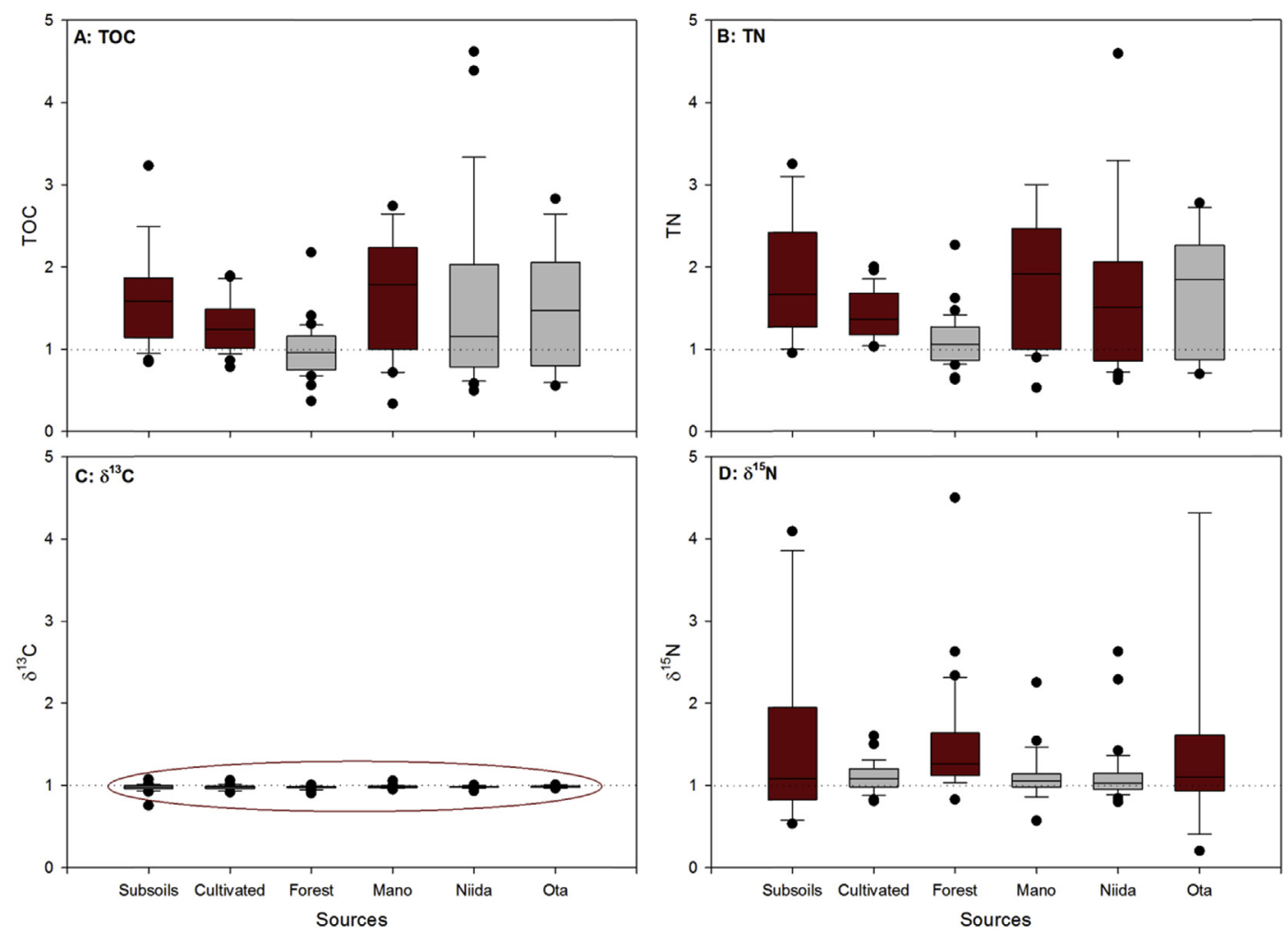

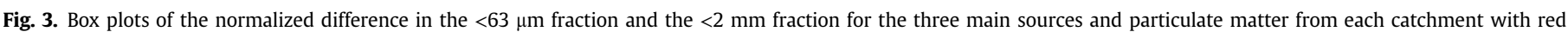

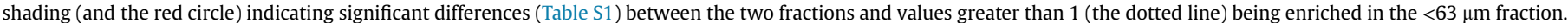
(For interpretation of the references to colour in this figure legend, the reader is referred to the web version of this article.)

indicative of the coarse nature of material being deposited within the river network in the Fukushima region after major rainfall events.

\subsection{Instream particulate matter}

Particulate matter parameters plotted across, and within, the TOC and TN source range suggesting this matter is derived from a mixture of surface, cultivated and subsoil sources in each catchment (Fig. 4). With the exception of one outlier, $\delta^{15} \mathrm{~N}$ plotted within the source range. There was one outlier for $\delta^{13} \mathrm{C}$ in the $<2 \mathrm{~mm}$ fraction and four in the $<63 \mu \mathrm{m}$ fraction. When comparing concentration dependent mixing lines for $\delta^{13} \mathrm{C}$, developed through solving Eq. (1) with the mean and one standard deviation plus and minus the mean and incremental 10\% mixture contributions from 0 to $100 \%$ for forest sources to subsoils sources (excluding cultivated sources) (Fig. 4), there is an evident negative shift in the $\delta^{13} \mathrm{C}$ ratios of particulate matter relative to their source ratios. This shift is postulated to derive from the occurrence of particulate organic matter, visibly evident in the both the $<2 \mathrm{~mm}$ and $<63 \mu \mathrm{m}$ fractions for multiple samples.

To understand the potential impact of this low particulate matter $\delta^{13} \mathrm{C}$ on source contributions, three approaches to incorporating elemental properties were modelled (i.e. C, N, C $+\mathrm{N}$ models). The $\mathrm{N}$ model includes particulate matter that plots within the source range. The $C$ model includes several particulate matter samples plotting below the source range for $\delta^{13} \mathrm{C}$. The $\mathrm{C}+\mathrm{N}$ model provides a combination of the two models, theoretically reducing the impact of $\delta^{13} \mathrm{C}$ on model results. Examining these results individually provides insight into potential different sources of particulate matter, whereas comparing them provides insight into performance of the different parameter combinations modelled. If the models are in close agreement, it provides further confidence into the source contribution results and suggests that the impact of the low $\delta^{13} \mathrm{C}$ ratios is off-set by other parameters during the modelling process.

\subsection{Modelling results}

Cultivated and forest source parameters were fit with normal 

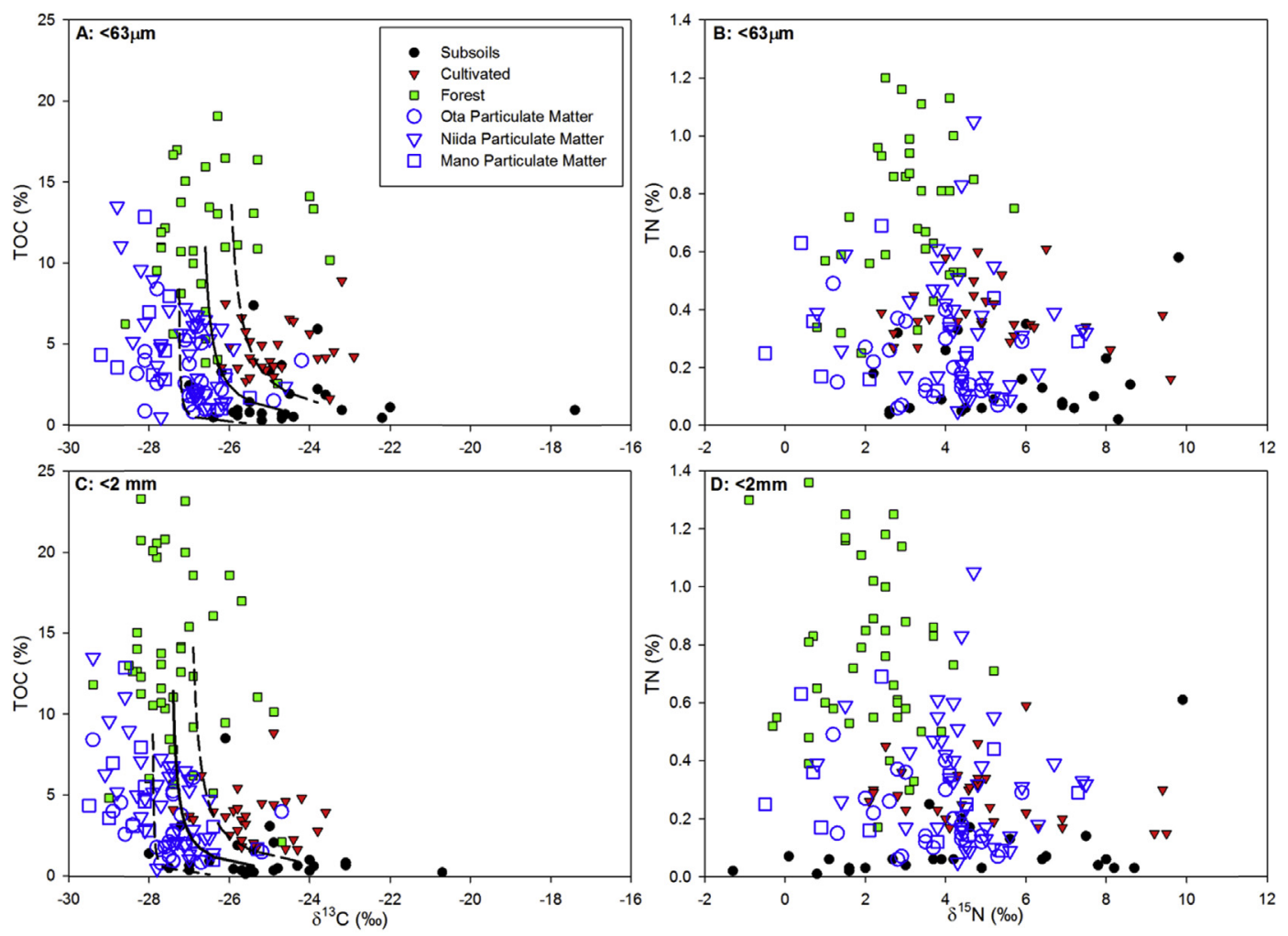

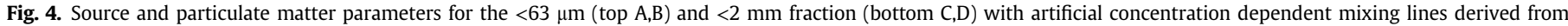
solving Eq. (1) with $10 \%$ increases of the mean (solid) and \pm 1 SD (dashed lines) as $x_{S}$ in Eq. (1) from 0 to $100 \%$ for subsoil and forest sources.

distributions for the $<63 \mu \mathrm{m}$ fraction with the exception of forest $\delta^{13} \mathrm{C}$ which was fit with a max-extreme (or Gumbel) distribution (Table S2). Subsoil TOC and TN were fit with log-normal distributions and subsoil $\delta^{15} \mathrm{~N}$ was fit with a normal distribution for the $<63 \mu \mathrm{m}$ fraction. For the $<2 \mathrm{~mm}$ fraction, TOC and TN were fit with log-normal distributions, with the exception of forest TN which was fit with a normal distribution and cultivated TOC which was fit with a logistic distribution. Normal distributions were fit for all $<2 \mathrm{~mm}$ fraction source $\delta^{13} \mathrm{C}$ and $\delta^{15} \mathrm{~N}$ except cultivated $\delta^{15} \mathrm{~N}$ which was fit with a max-extreme distribution. Subsoil TOC and TN were fit with log-normal distributions for both particle size fractions, likely resulting from their proximity to 0 . Correlations between concentration parameters were maintained during the modelling process, which is important when randomly sampling from TOC and TN distributions as they are highly correlated with a mean Pearson product-moment correlation coefficient of 0.965 (SD 0.023 ) for all TOC and TN source combinations including both particle size fractions (Table S3).

The impact of particle size on modelling results was most evident for cultivated and subsoil source contributions (Fig. S1). Forest sources predominantly plotted within one standard deviation of all modelled relative source differences plotted in Fig. S1 (SD $24.5 \%)$. Only $18 \%$ of modelled forest contribution differences plotted outside this global standard deviation compared to 30\% of cultivated sources and $46 \%$ of subsoil sources indicative of a larger particle size impact on subsoil and cultivated contributions. The forest source contributions in the $<63 \mu \mathrm{m}$ fraction were significantly different than the $<2 \mathrm{~mm}$ fraction for each modelling approach (Table S4). Although these differences were significant, forest sources were modelled to contribute only $11 \%$ more particulate matter with the $<63 \mu \mathrm{m}$ fraction than the $<2 \mathrm{~mm}$ fraction with the $\mathrm{N}$ model, $9 \%$ for the $\mathrm{C}+\mathrm{N}$ model and $5 \%$ for the $\mathrm{C}$ model. Although the deviation in relative contributions for the cultivated and subsoil sources is pronounced, the mean modelled differences between the $<2 \mathrm{~mm}$ and $<63 \mu \mathrm{m}$ fraction were less than $6 \%$, with no significant differences evident between subsoil contributions with the different particle size fractions and cultivated sources differing significantly for the $\mathrm{N}$ and $\mathrm{C}+\mathrm{N}$ models (Table S4). Although particle size visibly impacts modelled source contributions (Fig. S1), this particle size impact is partially addressed by having 72 particulate matter samples analyzed that likely mitigated the impacts of outliers, particularly for cultivated and subsoil sources, resulting in a mean difference of $6 \%$ (SD 3\%) between all modelled source contributions. The limited difference between mean modelled source contributions is likely related to the similar enrichment of tracer properties in both source and particulate matter samples (Fig. 3).

The impact of modelling different particulate matter parameters similarly was most pronounced for subsoils and cultivated sources (Fig. S2). Forest sources again predominantly plotted within one standard deviation of the global mean relative source difference for all particulate matter models (SD 14\%). There were $12 \%$ of the forest source contributions that plotted outside the global standard deviation, compared to $34 \%$ for cultivated sources and $23 \%$ for subsoil sources. The $\mathrm{C}$ and $\mathrm{N}$ models had the most pronounced differences in predicted source contributions with $37 \%$ of their source contribution differences plotting outside the $14 \%$ global standard deviation. The $\mathrm{C}$ and $\mathrm{C}+\mathrm{N}$ models had $23 \%$ of their source contribution differences plotting outside this global standard deviation, followed by only $8 \%$ for the $\mathrm{N}$ and $\mathrm{C}+\mathrm{N}$ model. The only significant difference between the $<2 \mathrm{~mm}$ modelled source contributions was for cultivated and subsoil sources with the $\mathrm{N}$ and $\mathrm{C}+\mathrm{N}$ models (Table 6S). Conversely, for the $<63 \mu \mathrm{m}$ fraction, source contributions were significantly different between most of the modelling combinations with the exception for subsoil ( $\mathrm{C}$ and $\mathrm{N}$ model) and cultivated source contributions ( $\mathrm{N}$ and $\mathrm{C}+\mathrm{N}$ model). Although 
there were clear impacts of the low $\delta^{13} \mathrm{C}$ particulate matter on modelled source contributions, where $\delta^{13} \mathrm{C}$ plays a large role (e.g. $<25 \%$ of the properties modelled - the $C$ model), the impact was less pronounced for forest sources in both particle size fractions and the impact of these different modelled properties resulted in a maximum $10 \%$ model difference in relative mean source contributions and only a $4 \%$ mean difference (SD 3\%) in source contributions for the entire modelled dataset.

As there were outliers evident when examining the relative source contributions with different particle size fractions (Fig. S1) and different models (Fig. S2), the spatial source contributions were grouped by upstream (coastal mountain range) and downstream (coastal plain) sampling location for each catchment and for each sampling campaign. The six different models (i.e. the $<2 \mathrm{~mm}$ and $<63 \mu \mathrm{m}$ for the $\mathrm{C}, \mathrm{N}$, and $\mathrm{C}+\mathrm{N}$ models) for each of the particulate matter samples were included in the median and MAD calculations when presenting the source contributions for these spatial groupings (i.e. upstream and coastal plain). Including the six different models into the median and MAD calculation in the spatial source contributions indirectly incorporates some of the potential impact of particle size and low $\delta^{13} \mathrm{C}$ particulate matter into the uncertainty (MAD) presented for the source contributions.

Cultivated source contributions were the highest in the Niida catchment (47\%, MAD 18\%) followed by the Ota (35\%, MAD 29\%) and Mano (21\%, MAD 19\%) catchments. Subsoil source contributions were highest in the Mano (66\%, MAD 15\%) followed by the Ota (44\%, MAD 28\%) and the Niida catchment (33\%, MAD 26\%). Importantly, there was a $0.4 \%$ (MAD $0.3 \%$ ) cultivated source contribution in the upstream portion of the Ota catchment confirming the source discrimination capacity of the model as this area is predominantly forested (Fig. 5). Forest contributions were highest in the Ota (20\%, MAD 13\%) and Niida (20\%, MAD 11\%) catchments, followed by the Mano (13\%, MAD 7\%) catchment. Each source contributed significantly in these three Fukushima Prefecture focal catchments.

Cultivated source contributions were highest in Spring 2013 (50\% MAD 20\%) (Fig. 5), followed by Fall 2013 (42\%, MAD 19\%) with their lowest contributions coming in Fall 2014 (29\%, MAD 24\%) and Fall 2012 (27\%, MAD 37\%). There was a corresponding increase in subsoil sources as the cultivated sources decreased with subsoils having their highest contribution in Fall 2012 (60\%, MAD 35\%) and Fall 2014 (54\%, MAD 23\%) and their lowest contributions in Spring 2013 (26\%, MAD 26\%) and Fall 2013 (38\%, MAD 21\%). Forest source contributions were consistent throughout the sampling campaigns ranging from 13\% (MAD 11\%) and 14\% (MAD 9\%) in Fall 2012 and Spring 2013 respectively to 17\% (MAD 8\%) in Fall 2014 and 20\% (MAD 11\%) in Fall 2013. The differences between upstream and downstream source contributions were limited with the maximum difference being only $4.1 \%$ for subsoil sources.

Forest sources were modelled to contribute almost one fifth of all particulate matter sampled (17\%, MAD 10\%) indicating that they represent a potential long term source of particulate-bound radiocesium in the region. Subsoils were modelled to contribute the most particulate matter (45\%, MAD 26\%) even in these heavily modified and channelized catchments. Cultivated soils contributed

\section{Fall 2012}

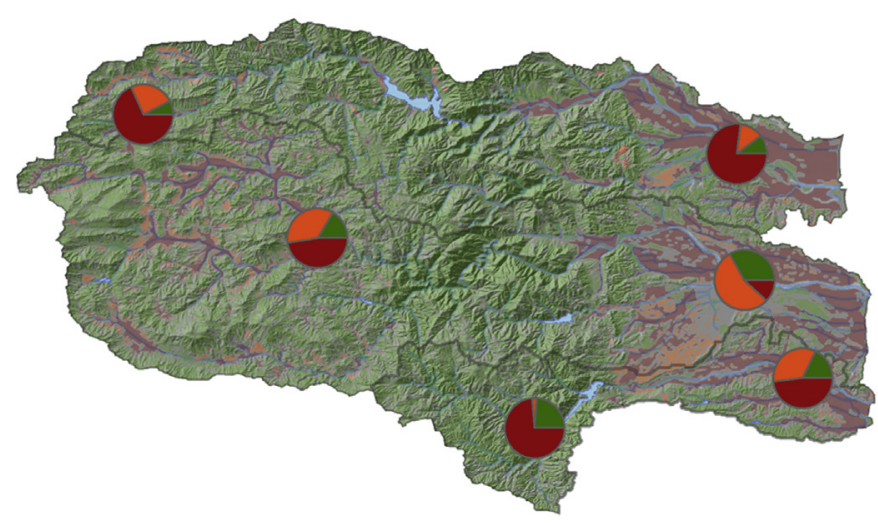

\section{Fall 2013}

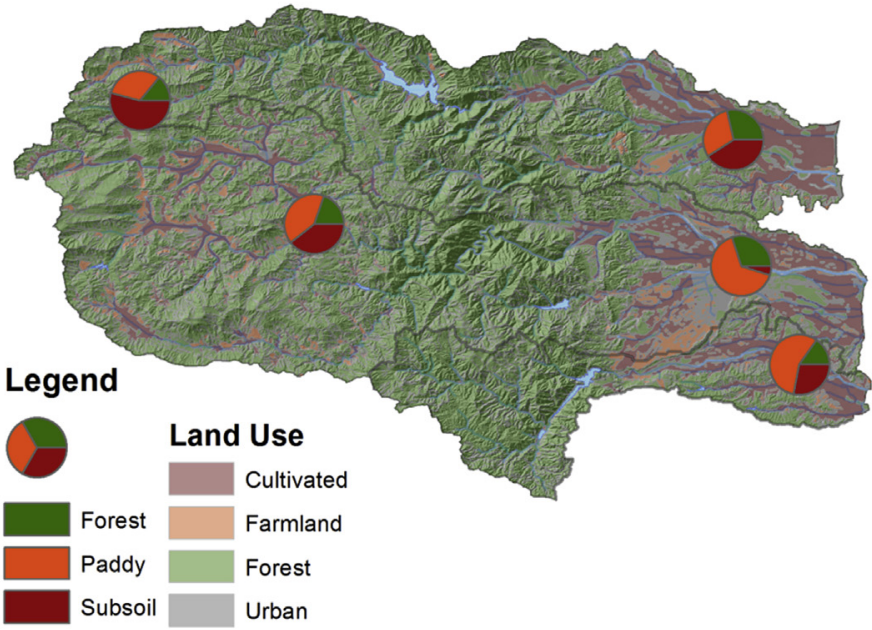

\section{Spring 2013}

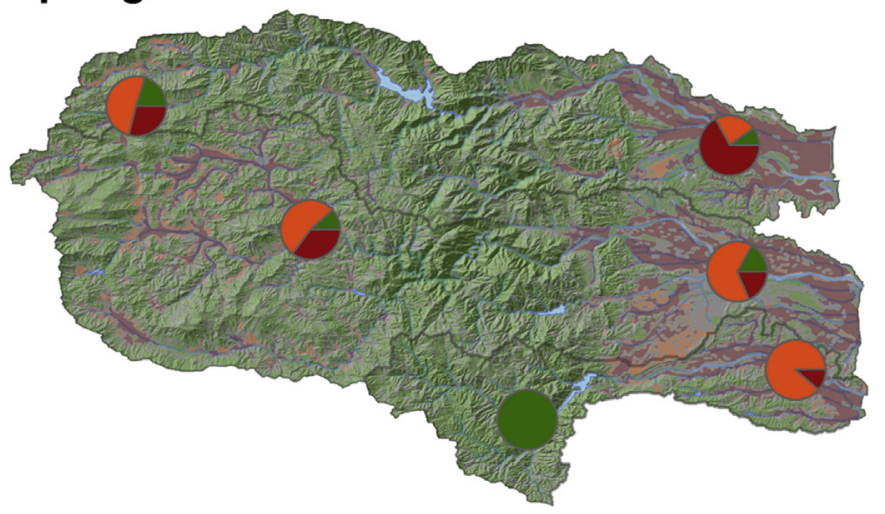

Fall 2014

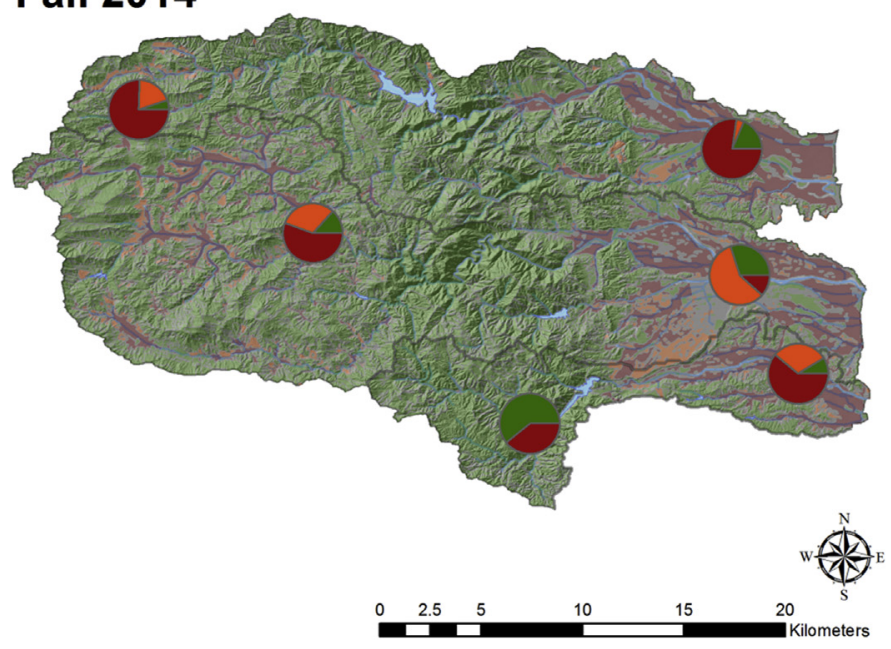

Fig. 5. Median source contributions for upstream (coastal mountain range) and downstream (coastal range) for each catchment and each sampling campaign. 
significantly (38\%, MAD 19\%) which is more than double the cultivated land use (16\%) in these catchments. All model results are provided in a supplementary file (File S1).

\section{Discussion}

\subsection{Source discrimination}

The original sampling design included seven sub-sources from three main categories. Within these sub-sources, only $\delta^{15} \mathrm{~N}$ provided significant discrimination between the standard cultivated and paddy sources for both the $<63 \mu \mathrm{m}$ and $<2 \mathrm{~mm}$ fractions demonstrating that there may be potential to discriminate between these two sub-sources in similar regions. There were no other particulate matter parameters that provided significant discrimination between sub-sources for both particle size fractions. Accordingly the three main categories (i.e. subsoils, cultivated and forests) were modelled with three different approaches (i.e. C, N, $\mathrm{C}+\mathrm{N}$ ) to quantify source contributions. The discrimination potential of these particulate matter parameters was similar to other applications in sediment tracing research (Fox and Papanicolaou, 2007; Laceby et al., 2015b; Mukundan et al., 2010; Papanicolaou et al., 2003).

These three main source categories discriminated between $~ 80 \%$ of the possible source combinations. Only $\delta^{13} \mathrm{C}$ and $\delta^{15} \mathrm{~N}$ did not discriminate between subsoil and cultivated sources likely resulting in the greater deviation in relative source contributions for these two sources compared to forest sources. In this case, the source with the most element parameter discrimination, forests (100\%), had more consistent model performance for both particle size fractions and the three model approaches than cultivated and subsoils (both $50 \%$ ) which had greater relative source contribution deviations (Figs. S1 and S2). More research is warranted on exploring this effect of reduced deviation in source contributions with increased tracer parameter discrimination between sources.

\subsection{Particle size}

Although $\delta^{13} \mathrm{C}$ was enriched in the $<63 \mu \mathrm{m}$ fraction, this enrichment was less than $5 \%$ compared to a mean enrichment of $25 \%$ in the $<63 \mu \mathrm{m}$ fraction for the other three parameters. The only properties that were not enriched were TOC and TN in forest soils and $\delta^{15} \mathrm{~N}$ in cultivated sources. Laceby et al. (2015b) also reported a similar significant, though minor enrichment for $\delta^{13} \mathrm{C}$ across multiple particle size fractions. These authors also reported a significant enrichment in TOC and TN when combining multiple source samples (e.g. grazing, cultivated, and subsoils). Here, we demonstrated that there is within-source variation in the particle size enrichment for TOC, TN and $\delta^{15} \mathrm{~N}$ (Table S1, Fig. 3) with nonsignificant enrichment in forest samples for TOC and TN and cultivated samples with $\delta^{15} \mathrm{~N}$. This reinforces the variety of potential relationships between particle size and particulate matter parameters possible for each source as illustrated for elemental geochemistry by Russell et al. (2001) and Smith and Blake (2014). Although fluvial sorting processes during sediment mobilization, transport and deposition are hypothesized to result in enrichment in particulate matter properties, the extent and consistency of this potential enrichment requires more research.

The particle size analyses demonstrated a general enrichment of parameters for both the sources and for the particulate matter properties. The mutual enrichment likely resulted in the mean model difference between the particle size fractions of only 6\% (SD $3 \%$ ). Although this difference seems minor, it was significant and likely mitigated by the 71 particulate matter samples. In comparison, Haddadchi et al. (2015) reported that there was an absolute mean difference of $14 \%$ (SD $8 \%$ ) between the $<10 \mu \mathrm{m}$ and the 10-63 $\mu \mathrm{m}$ and 13\% (SD 9\%) between the $<10 \mu \mathrm{m}$ and the 63-212 $\mu \mathrm{m}$ fraction. The larger mean differences and standard deviations reported by these authors likely relates to the fact that they compared isolated fraction ranges, they used elemental geochemistry which is inherently more complex, and they modelled only 8 sediment samples for comparison. Based on the results of this current research, it is probable that with increasing sample size, the likelihood of particle size impacts on source apportionment results may decrease as outliers will have less impact on the overall results. Indeed this suggests that there could be significant benefits for sediment tracing and fingerprinting research to increase not only the number of source samples (e.g., Olley et al. (2013)), but also the amount of sediment or particulate matter samples to mitigate particle size impacts on modelling results.

\subsection{Particulate matter properties}

Particulate matter TOC, TN and $\delta^{15} \mathrm{~N}$ plotted within the source range (Fig. 4). Interestingly, particulate matter $\delta^{13} \mathrm{C}$ appeared to shift below the source range. As the particle size enrichment in $\delta^{13} \mathrm{C}$ is only $3 \%$, this shift is probably indicative of a missing or undersampled source. With the focus of this research being the investigation of particulate matter sources, the mineral (i.e. $<10 \mu \mathrm{m}$ ) fraction was not targeted. Thus organic matter was specifically not floated, sieved or picked out of the $<63 \mu \mathrm{m}$ or $<2 \mathrm{~mm}$ fractions resulting in non-mineral bound organic matter potentially being analyzed in the $<63 \mu \mathrm{m}$ fraction samples. This suggests that unless particulate organic matter is directly removed during sample preparation, the $<63 \mu \mathrm{m}$ fraction will likely not be constituted completely of mineral-bound organic matter.

In Japan and elsewhere, leaf litter and vegetation debris have been reported to have lower $\delta^{13} \mathrm{C}$ than soil organic matter (Fig. 6) (Koarashi et al., 2005; von Fischer and Tieszen, 1995). This low $\delta^{13} \mathrm{C}$ material may be derived from forest hillslopes during erosive events or even from proximal sources (e.g. riparian vegetation) prior to sampling. For researchers interesting in the mineral fraction, removal of organic debris by floating or density separation may be warranted. Moreover, additional analyses, such as compound specific isotopes (Blake et al., 2012; Cooper et al., 2015; Hancock and Revill, 2013) could provide increased source discrimination and insights into potential contributions from instream particulate matter. Analyses into the sources of carbon, including the use of vegetation as an end-member in particulate matter source tracing (Garzon-Garcia et al., in review) could provide additional significant insights into carbon sources in the catchment and potentially global carbon fluxes through the development of field based approaches that may be capable of validating desktop-based carbon flux models (e.g. Ciais et al., 2008; Doetterl et al., 2012).

In the Fukushima region, radiocesium contamination is found in leaves, leaf litter and soil organic matter (Hashimoto et al., 2012; Koarashi et al., 2012; Loffredo et al., 2014). Therefore, the particulate matter was traced in both the bulk $(<2 \mathrm{~mm})$ and fine $(<63 \mu \mathrm{m})$ fractions. To understand and incorporate the impact of the potential missing source of low $\delta^{13} \mathrm{C}$ particulate matter three modelling approaches were adopted (i.e. $\mathrm{C}, \mathrm{N}$, and $\mathrm{C}+\mathrm{N}$ ). Although there were significant differences between modelling approaches, the maximum model difference was only $10 \%$ and the global standard deviation of relative modelled source contributions with the different models (14\%) was less than what was observed between the two particle size fractions (25\%). The limited differences between modelled source contributions (mean 4\%, SD 3\%) indicate that the low $\delta^{13} \mathrm{C}$ particulate matter from several samples does not 

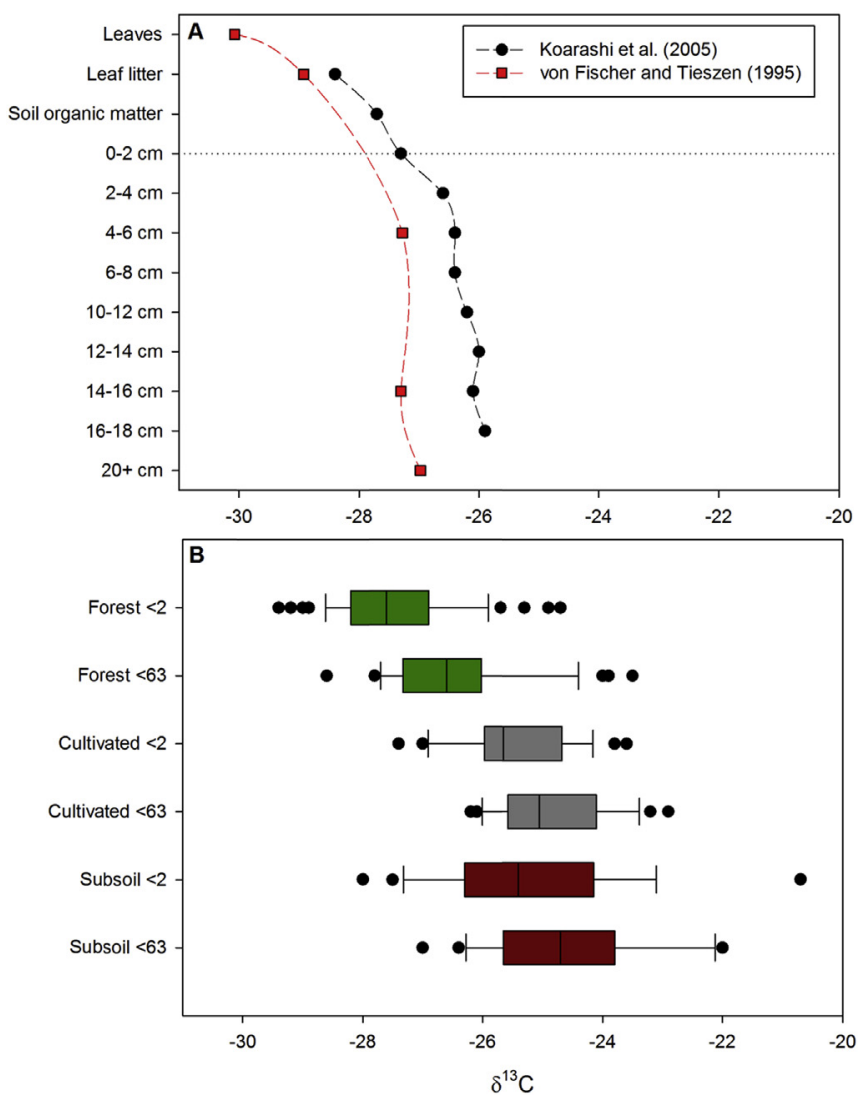

Fig. 6. Soil profile $\delta^{13} \mathrm{C}$ including leaves, leaf litter and soil organic matter from research in Japan (Koarashi et al., 2005) and Puerto Rico (von Fischer and Tieszen, 2005) (Top - A) along with the box plots from the source samples taken in this current research from the three Fukushima catchments (bottom - B).

substantially impact the model results. This mitigation of the impact of the low $\delta^{13} \mathrm{C}$ particulate matter suggests that it may be disadvantageous to focus on reducing the number of tracers being modelled and that small sample sizes may negatively impact the accuracy of source contributions.

To include the impact of both particle sizes and the low $\delta^{13} \mathrm{C}$ particulate matter, the results from six different model iterations were included in the source contributions that were determined for catchment regions (i.e. upstream and downstream) and multiple sampling campaigns to further incorporate the potential impact of outlying source contributions. This approach increases model uncertainties though it provides a broader incorporation of multiple uncertainties (e.g. particle size and potential non-conservative behavior). The limited differences for the modelled source contributions between the different modelling approaches (mean 4\%, SD $3 \%$ ) and the different particle size fractions (mean 6\%, SD 3\%) provides further confidence to these grouped spatial modelling results. Although this multi-modelling approach may have helped constrain the reliability of particulate matter source identification, there are multiple instream processes, such as organic matter mineralization, nitrogen transformations and potential autochthonous sources that may impact source allocations. The potential impact of these processes on different particulate matter components and parameters requires further research.

\subsection{Management implications}

Forest sources contributed 17\% (SD 10\%) of particulate matter sampled in the three Fukushima coastal catchments. These results were similar to that of Kitamura et al. (2014) who modelled that forest sources account for $24 \%$ of the soil loss in the region. The forests in the Fukushima region are not only a reservoir of radiocesium contaminated particulate matter; they are also a potential source of contaminated matter that may be transferred downstream during erosive rainfall events.

Subsoils were modelled to supply the most particulate matter (45\%, SD 26\%). At first, this result is counterintuitive as the majority of the river network appears to be highly engineered with river banks sealed with cement in these catchments. However, after a significant erosive rainfall event in September 2015 (i.e. Tropical Storm Etau), some landslides were evident along with other smallscale hillslope failures and channel bank erosion in small headwater, non-engineered reaches confirming the potential of subsoil erosion to provide a significant source of particulate matter. This significance of subsoil sources should be incorporated into future radiocesium and sediment modelling in this region. Further, this subsoil material may also be derived from decontaminated sources, particularly paddy fields, which are highly connected to the river network. As recently decontaminated eroded subsoil material will not contain fallout from the FDNPP accident, this material will likely dilute radiocesium contaminated material recently eroded from surface sources, potentially impacting modelling estimates of radiocesium and sediment fluxes in this region.

Cultivated soils contributed 38\% (SD 19\%) of the sampled particulate matter, a contribution that was more than double their spatial extent. The decontamination approach of removing the top $5 \mathrm{~cm}$ of these cultivated sources is likely contributing to the reduction of downstream radiocesium concentrations (Evrard et al., in review). As cultivated sources are progressively decontaminated, the focus must shift to managing the radiocesium contamination of forests in the region impacted by FDNPP fallout.

\section{Conclusions}

Each of the three major sources (i.e. forests, cultivated soils and subsoils) contributed particulate matter downstream. Forests contributed $17 \%$ (SD 10\%) of particulate matter indicating they are a long-term source of radiocesium contaminated particulate matter in fallout impacted catchments. Subsoils contributed 45\% (SD 26\%) of particulate matter, indicating they are the most dominant source of matter that should be incorporated into desktop models predicting future sediment fluxes as they may dilute radiocesium concentrations on sediment and particulate matter samples used to calibrate models. Cultivated sources contributed 38\% (SD 19\%) of the particulate matter, more than double their surface extent, confirming that they should be prioritized for decontamination in this region.

Although particle size did significantly impact the tracer parameters, the modelling results for the $<63 \mu \mathrm{m}$ and $<2 \mathrm{~mm}$ size fractions only differed by a maximum mean source contribution of $11 \%$. Similarly, the different particulate matter properties modelled resulted in significantly different source contributions though with a maximum difference in the mean source contribution of only $10 \%$. On one hand, these results demonstrate the potential impact of tracer properties and particle size. On the other hand, they also indicate that with larger sample sizes these differences may be mitigated, whereas with smaller samples sizes, outliers will likely have a greater impact on modelled source contributions. Including source apportionment results from modelling different particle size and particulate matter properties provides an alternative approach to understanding and incorporating a broader conceptualization of model uncertainty, including potential deviation derived from particle size and source parameter variation. 


\section{Acknowledgements}

This work was funded by the French National Research Agency AMORAD project (ANR-11-RSNR-0002). Philippe Bonté, Olivier Cerdan, Irène Lefèvre, Caroline Chartin, Hugo Lepage, Yoshifumi Wakiyama, and Jeremy Patin's assistance with fieldwork and Gabin Archimbault's assistance with lab work are greatly appreciated.

\section{Appendix A. Supplementary data}

Supplementary data related to this article can be found at http:// dx.doi.org/10.1016/j.jenvman.2016.09.020.

\section{References}

Agnihotri, R., Kumar, R., Prasad, M., Sharma, C., Bhatia, S., Arya, B., 2014. Experimental setup and standardization of a continuous flow stable isotope mass spectrometer for measuring stable isotopes of carbon, nitrogen and sulfur in environmental samples. Mapan 29, 195-205.

Amundson, R., Austin, A.T., Schuur, E.A.G., Yoo, K., Matzek, V., Kendall, C., Uebersax, A., Brenner, D., Baisden, W.T., 2003. Global patterns of the isotopic composition of soil and plant nitrogen. Glob. Biogeochem. Cycles 17, 1031.

Bailey, S., 1980. Structures of layer silicates. In: Brindley, G.W., Brown, G. (Eds.), Crystal Structures of Clay Minerals and Their X-ray Identification. Oxford University Press, Oxford, p. 495.

BCJ, 2016. Biodiversity Centre of Japan (BJC) National Environmental Information GIS. Ministry of the Environment, Fujiyoshida City, Yamanashi Prefecture.

Blake, W., Walsh, R., Sayer, A., Bidin, K., 2006. Quantifying fine-sediment sources in primary and selectively logged rainforest catchments using geochemical tracers. Water Air Soil Poll. 6, 615-623.

Blake, W.H., Ficken, K.J., Taylor, P., Russell, M.A., Walling, D.E., 2012. Tracing cropspecific sediment sources in agricultural catchments. Geomorphology 139-140, 322-329.

Chartin, C., Evrard, O., Onda, Y., Laceby, P., Cerdan, O., Lepage, H., Ottlé, C., Lefèvre, I., Bonté, P., in review. The impact of typhoons on sediment connectivity: lessons learnt from contaminated coastal catchments in the Fukushima Prefecture (Japan). Earth Surf. Proc. Land.

Chartin, C., Evrard, O., Onda, Y., Patin, J., Lefèvre, I., Ottlé, C., Ayrault, S., Lepage, H., Bonté, P., 2013. Tracking the early dispersion of contaminated sediment along rivers draining the Fukushima radioactive pollution plume. Anthropocene 1, $23-34$.

Chino, M., Nakayama, H., Nagai, H., Terada, H., Katata, G., Yamazawa, H., 2011. Preliminary estimation of release amounts of ${ }^{131} \mathrm{I}$ and ${ }^{137} \mathrm{Cs}$ accidentally discharged from the Fukushima Daiichi nuclear power plant into the atmosphere. J. Nucl. Sci. Technol. 48, 1129-1134.

Ciais, P., Borges, A.V., Abril, G., Meybeck, M., Folberth, G., Hauglustaine, D., Janssens, I.A., 2008. The impact of lateral carbon fluxes on the European carbon balance. Biogeosciences 5, 1259-1271.

Collins, A.L., Walling, D.E., 2004. Documenting catchment suspended sediment sources: problems, approaches and prospects. Prog. Phys. Geoggr. 28, 159-196.

Cooper, R.J., Pedentchouk, N., Hiscock, K.M., Disdle, P., Krueger, T., Rawlins, B.G., 2015. Apportioning sources of organic matter in streambed sediments: an integrated molecular and compound-specific stable isotope approach. Sci. Total Environ. 520, 187-197.

Coplen, T.B., Kendall, C., Hopple, J., 1983. Comparison of stable isotope reference samples. Nature 302, 236-238.

Davis, C.M., Fox, J.F., 2009. Sediment fingerprinting: review of the method and future improvements for allocating nonpoint source pollution. J. Environ. EngASCE 135, 490-504.

Doetterl, S., Van Oost, K., Six, J., 2012. Towards constraining the magnitude of global agricultural sediment and soil organic carbon fluxes. Earth Surf. Proc. Land 37, 642-655.

Dytham, C., 2003. Choosing and Using Statistics, a Biologist's Guide, second ed. Blackwell Publishing, Oxford.

Evrard, O., Chartin, C., Onda, Y., Lepage, H., Cerdan, O., Lefevre, I., Ayrault, S., 2014. Renewed soil erosion and remobilisation of radioactive sediment in Fukushima coastal rivers after the 2013 typhoons. Sci. Rep. 4.

Evrard, O., Laceby, J.P., Huon, S., Lefèvre, I., Sengtaheuanghoung, O., Ribolzi, O., 2016. Combining multiple fallout radionuclides $\left({ }^{137} \mathrm{Cs},{ }^{7} \mathrm{Be},{ }^{210} \mathrm{~Pb}_{\mathrm{xs}}\right)$ to investigate temporal sediment source dynamics in tropical, ephemeral riverine systems. J. Soils Sediments 16, 1130-1144.

Evrard, O., Laceby, J.P., Lepage, H., Onda, Y., Cerdan, O., Ayrault, S., 2015. Radiocesium transfer from hillslopes to the pacific ocean after the Fukushima nuclear power plant accident: a review. J. Environ. Radioact. 148, 92-110.

Evrard, O., Laceby, J.P., Onda, Y., Wakiyama, Y., Jaegler, H., Lefèvre, I., in review. Quantifying the dilution of the initial radioactive contamination in Fukushima coastal river sediment from decontamination and typhoons (2011-2015). Sci. Rep..

Feller, C., Beare, M., 1997. Physical control of soil organic matter dynamics in the tropics. Geoderma 79, 69-116.
Foucher, A., Laceby, J.P., Salvador-Blanes, S., Evrard, O., Le Gall, M., Lefèvre, I., Cerdan, O., Rajkumar, V., Desmet, M., 2015. Quantifying the dominant sources of sediment in a drained lowland agricultural catchment: the application of a thorium-based particle size correction in sediment fingerprinting. Geomorphology 250, 271-281.

Fox, J.F., Papanicolaou, A.N., 2007. The use of carbon and nitrogen isotopes to study watershed erosion processes. J. Am. Water Resour. As 43, 1047-1064.

Fry, B., 2006. Stable Isotope Ecology. Springer. New York.

Garzon-Garcia, A., Laceby, J.P., Olley, J.M., Bunn, S.E., in review. Differentiating the sources of fine sediment and particulate carbon and nitrogen in a subtropical Australian catchment. Sci. Total Environ..

Girardin, C., Mariotti, A., 1991. Analyse isotopique du ${ }^{13} \mathrm{C}$ en abondance naturelle dans le carbone organique: un système automatique avec robot préparateur. Cah. ORSTOM. Ser. Pedofil 26, 371-380.

Gourdin, E., Huon, S., Evrard, O., Ribolzi, O., Bariac, T., Sengtaheuanghoung, O., Ayrault, S., 2015. Sources and export of particle-borne organic matter during a monsoon flood in a catchment of northern Laos. Biogeosciences 12, 1073-1089.

Gregorich, E., Beare, M., McKim, U., Skjemstad, J., 2006. Chemical and biologica characteristics of physically uncomplexed organic matter. Soil Sci. Soc. Am. J. 70 975-985.

Groëll, J., Quélo, D., Mathieu, A., 2014. Sensitivity analysis of the modelled deposition of ${ }^{137} \mathrm{Cs}$ on the Japanese land following the Fukushima accident. Int. J. Environ. Pollut. 55, 67-75.

Guzmán, G., Quinton, J., Nearing, M., Mabit, L., Gómez, J., 2013. Sediment tracers in water erosion studies: current approaches and challenges. J. Soils Sediments 13 , 816-833.

Haddadchi, A., Olley, J., Laceby, J.P., 2014. Accuracy of mixing models in predicting sediment source contributions. Sci. Total Environ. 497-498, 139-152.

Haddadchi, A., Olley, J., Pietsch, T., 2015. Quantifying sources of suspended sediment in three size fractions. J. Soils Sediments 15, 2086-2100.

Haddadchi, A., Ryder, D.S., Evrard, O., Olley, J., 2013. Sediment fingerprinting in fluvial systems: review of tracers, sediment sources and mixing models. Int. J. Sediment. Res. 28, 560-578.

Hancock, G.J., Revill, A.T., 2013. Erosion source discrimination in a rural Australian catchment using compound-specific isotope analysis (CSIA). Hydrol. Process 27, 923-932.

Hashimoto, S., Matsuura, T., Nanko, K., Linkov, I., Shaw, G., Kaneko, S., 2013. Predicted spatio-temporal dynamics of radiocesium deposited onto forests following the Fukushima nuclear accident. Sci. Rep. 3.

Hashimoto, S., Ugawa, S., Nanko, K., Shichi, K., 2012. The total amounts of radioactively contaminated materials in forests in Fukushima, Japan. Sci. Rep. 2.

Juracek, K.E., Ziegler, A.C., 2009. Estimation of sediment sources using selected chemical tracers in the Perry lake basin, Kansas, USA. Int. J. Sediment. Res. 24 $108-125$

Kato, H., Onda, Y., Gomi, T., 2012. Interception of the Fukushima reactor accidentderived ${ }^{137} \mathrm{Cs},{ }^{134} \mathrm{Cs}$ and ${ }^{131} \mathrm{I}$ by coniferous forest canopies. Geophys. Res. Lett. 39.

Kitamura, A., Yamaguchi, M., Kurikami, H., Yui, M., Onishi, Y., 2014. Predicting sediment and cesium-137 discharge from catchments in eastern Fukushima. Anthropocene 5, 22-31.

Koarashi, J., Atarashi-Andoh, M., Matsunaga, T., Sato, T., Nagao, S., Nagai, H., 2012. Factors affecting vertical distribution of Fukushima accident-derived radiocesium in soil under different land-use conditions. Sci. Total Environ. 431, 392-401.

Koarashi, J., Iida, T. Asano, T., 2005. Radiocarbon and stable carbon isotope compositions of chemically fractionated soil organic matter in a temperate-zone forest. J. Environ. Radioact. 79, 137-156.

Koiter, A., Owens, P., Petticrew, E., Lobb, D., 2013. The behavioural characteristics of sediment properties and their implications for sediment fingerprinting as an approach for identifying sediment sources in river basins. Earth-Sci. Rev. 125 24-42.

Laceby, J.P., Chartin, C., Evrard, O., Onda, Y., Garcia-Sanchez, L., Cerdan, O., 2016. Rainfall erosivity in catchments contaminated with fallout from the Fukushima Daiichi nuclear power plant accident. Hydrol. Earth Syst. Sci. 20, 2467-2482.

Laceby, J.P., McMahon, J., Evrard, O., Olley, J., 2015a. A comparison of geological and statistical approaches to element selection for sediment fingerprinting. J. Soils Sediments 15, 2117-2131.

Laceby, J.P., Olley, J., 2015. An examination of geochemical modelling approaches to tracing sediment sources incorporating distribution mixing and elemental correlations. Hydrol. Process 29, 1669-1685.

Laceby, J.P., Olley, J., Pietsch, T.J., Sheldon, F., Bunn, S.E., 2015b. Identifying subsoil sediment sources with carbon and nitrogen stable isotope ratios. Hydrol. Process 29, 1956-1971.

Le Gall, M., Evrard, O., Foucher, A., Laceby, J.P., Salvador-Blanes, S., Thil, F., Dapoigny, A., Lefèvre, I., Cerdan, O., Ayrault, S., 2016. Quantifying sediment sources in a pond draining a lowland agricultural catchment using ${ }^{137} \mathrm{Cs}$ ac tivities and radiogenic ${ }^{87} \mathrm{Sr} /{ }^{86} \mathrm{Sr}$ ratios. Sci. Total Environ. 566-567, 968-980.

Lepage, H., Evrard, O., Onda, Y., Lefèvre, I., Laceby, J.P., Ayrault, S., 2015. Depth distribution of cesium-137 in paddy fields across the Fukushima pollution plume in 2013. J. Environ. Radioact. 147, 157-164.

Lepage, H., Laceby, J.P., Bonté, P., Joron, J.-L., Onda, Y., Lefèvre, I., Ayrault, S., Evrard, O., 2016. Investigating the source of radiocesium contaminated sediment in two Fukushima coastal catchments with sediment tracing techniques. Anthropocene 13, 57-68.

Loffredo, N., Onda, Y., Kawamori, A., Kato, H., 2014. Modeling of leachable ${ }^{137}$ Cs in 
throughfall and stemflow for japanese forest canopies after Fukushima Daiichi nuclear power plant accident. Sci. Total Environ. 493, 701-707.

Lützow, M.v., Kögel-Knabner, I., Ekschmitt, K., Matzner, E., Guggenberger, G., Marschner, B., Flessa, H., 2006. Stabilization of organic matter in temperate soils: mechanisms and their relevance under different soil conditions-a review. Eur. J. Soil Sci. 57, 426-445.

Mariotti, A., Peterschmitt, E., 1994. Forest savanna ecotone dynamics in India as revealed by carbon isotope ratios of soil organic matter. Oecologia 97, 475-480.

Matsuda, N., Mikami, S., Shimoura, S., Takahashi, J Nakano, M. Shimada, K, Uno, K. Hagiwara, S., Saito, K., 2015. Depth profiles of radioactive cesium in soil using a scraper plate over a wide area surrounding the Fukushima Dai-ichi Nuclear Power Plant. Jpn. J. Environ. Radioact. 139, 427-434.

McConnachie, J.L., Petticrew, E.L., 2006. Tracing organic matter sources in riverine suspended sediment: implications for fine sediment transfers. Geomorphology $79,13-26$.

Mikutta, R., Kleber, M., Torn, M.S., Jahn, R., 2006. Stabilization of soil organic matter: association with minerals or chemical recalcitrance? Biogeochemistry 77, 25-56.

Mukundan, R., Radcliffe, D.E., Ritchie, J.C., Risse, L.M., Mckinley, R.A., 2010. Sediment fingerprinting to determine the source of suspended sediment in a southern piedmont stream. J. Environ. Qual. 39, 1328-1337.

Natelhoffer, K.J., Fry, B., 1988. Controls on natural nitrogen-15 and carbon-13 abundances in forest soil organic matter Soil Sci. Soc. Am. J. 52, 1633-1640.

Olley, J., Burton, J., Smolders, K., Pantus, F., Pietsch, T., 2013. The application of fallout radionuclides to determine the dominant erosion process in water supply catchments of subtropical South-east Queensland, Australia. Hydrol. Process 27, 885-895.

Owens, P.N., Blake, W.H., Petticrew, E.L., 2006. Changes in sediment sources following wildfire in mountainous terrain: a paired-catchment approach, british Columbia, Canada. In: Kronvang, B., Faganeli, J., Ogrinc, N. (Eds.), The Interactions between Sediments and Water. Springer Netherlands, pp. 273-281.

Papanicolaou, A.N., Fox, J.F., Marshall, J., 2003. Soil fingerprinting in the palouse basin, USA using stable carbon and nitrogen isotopes. Int. J. Sediment. Res. 18, $278-284$.

Remusat, L., Hatton, P.-J., Nico, P.S., Zeller, B., Kleber, M., Derrien, D., 2012. NanoSIMS study of organic matter associated with soil aggregates: advantages, limitations, and combination with STXM. Environ. Sci. Technol, 46, 3943-3949.

Russell, M.A., Walling, D.E., Hodgkinson, R.A., 2001. Suspended sediment sources in two small lowland agricultural catchments in the UK. J. Hydrol. 252, 1-24.

Saito, K., Onda, Y., 2015. Outline of the national mapping projects implemented after the Fukushima accident. J. Environ. Radioact. 139, 240-249.

Saito, T., Makino, H., Tanaka, S., 2014. Geochemical and grain-size distribution of radioactive and stable cesium in Fukushima soils: implications for their long term behavior. J. Environ. Radioact. 138, 11-18

Sakai, M., Gomi, T., Nunokawa, M., Wakahara, T. Onda, Y., 2014. Soil removal as a decontamination practice and radiocesium accumulation in tadpoles in rice paddies at Fukushima. Environ. Pollut. 187, 112-115.

Sawhiney, B., 1972. Selective sorption and fixation of cations by clay minerals: a review. Clay. Clay Min. 20, 93-100.

Schimel, D.S., 1993. Theory and Application of Tracers. Academic Press, Inc., San Diego.

Shinomiya, Y., Tamai, K., Kobayashi, M., Ohnuki, Y., Shimizu, T., Iida, S.I., Nobuhiro, T. Sawano, S., Tsuboyama, Y., Hiruta, T., 2014. Radioactive cesium discharge in stream water from a small watershed in forested headwaters during a typhoon flood event. Soil Sci. Plant Nutr. 60, 765-771.

Smith, H.G., Blake, W.H., 2014. Sediment fingerprinting in agricultural catchments: a critical re-examination of source discrimination and data corrections. Geomorphology 204, 177-191.

Sokal, R.R., Rohlf, F.J., 1981. Biometry: the principles and practice of statistics in biological research. WH Feeman \& Co., San Francisco, California.

Tanaka, K., Iwatani, H., Sakaguchi, A., Takahashi, Y., Onda, Y., 2014. Relationship between particle size and radiocesium in fluvial suspended sediment related to the Fukushima Daiichi Nuclear Power Plant accident. J. Radioanal. Nucl. Chem. 301, 607-613.

Vogel, C., Mueller, C.W., Höschen, C., Buegger, F., Heister, K., Schulz, S., Schloter, M., Kögel-Knabner, I., 2014. Submicron structures provide preferential spots for carbon and nitrogen sequestration in soils. Nat. Commun. 5.

von Fischer, J.C., Tieszen, L.L., 1995. Carbon Isotope Characterization of Vegetation and Soil Organic Matter in Subtropical Forests in Luquillo. Biotropica, Puerto Rico, pp. 138-148.

Walling, D.E., Woodward, J.C., 1995. Tracing sources of suspended sediment in river basins - a case-study of the River Culm, Devon, UK. Mar. Freshw. Res. 46, 327-336.

Wilkinson, S., Olley, J., Furuichi, T., Burton, J., Kinsey-Henderson, A., 2015. Sediment source tracing with stratified sampling and weightings based on spatial gradients in soil erosion. J. Soils Sediments 15, 2038-2051.

Yasutaka, T., Naito, W., 2016. Assessing cost and effectiveness of radiation decontamination in Fukushima Prefecture. Jpn. J. Environ. Radioact. 151, 512-520.

Yoshimura, K., Onda, Y., Kato, H., 2015. Evaluation of radiocaesium wash-off by soil erosion from various land uses using USLE plots. J. Environ. Radioact. 139, $362-369$.

Zirbser, K., Healy, R., Stahl, L., Tate, B., 2001. Methods for collection, storage and manipulation of sediments for chemical and toxicological analyses: technical manual. United States Environmental Protection Agency, Office of Science \& Technology, Washington, DC. 